\title{
Surgical lobectomy of pulmonary arteriovenous malformations in a patient with presentations regarded as sequela of tuberculosis: a case report
}

\author{
Peng Teng, Weidong Li and Yiming $\mathrm{Ni}^{*}$ (D)
}

\begin{abstract}
Background: Pulmonary arteriovenous malformations are uncommon conditions of abnormal communications between pulmonary arteries and veins, which are most commonly congenital in nature. Although such condition is not extremely rare, it is a challenge to the differential diagnosis of pulmonary problems such as hypoxemia and pulmonary lesions.

Case presentation: We report a meaningful case of a 23-year-old male presented with elevated hemoglobin $(23.0 \mathrm{~g} / \mathrm{dl})$ on admission. Physical examination revealed cyanosis, digital clubbing and low oxygen saturation on room air. The patient was initially diagnosed as polycythemia vera while the subsequent result of bone marrow aspiration was negative. During further assessment, pulmonary arteriovenous malformations were detected by $C T$ pulmonary angiography. Lobectomy was successfully performed with significant increase in oxygen saturation from 86 to $98 \%$. The hemoglobin decreased to almost normal level of $14.9 \mathrm{~g} / \mathrm{dl} 3$ months after surgery and the patient had been followed up for nearly 5 years.

Conclusions: Pulmonary arteriovenous malformations should be suspected in patients with central cyanosis, digital clubbing, polycythemia, pulmonary lesion and without cardiac malformations. Embolization or surgery is strongly recommended to reduce the risks caused by pulmonary arteriovenous malformations.
\end{abstract}

Keywords: Pulmonary arteriovenous malformation, Polycythemia, Cyanosis, Digital clubbing

\section{Introduction}

Pulmonary arteriovenous malformations (PAVMs) represent an uncommon disease with a latest estimated incidence of approximately 1 in 2630 in population scanned by chest CT [1]. It was first described by Churton in 1897 [2]. Owing to the lack of intervening capillary bed, the patients with PAVMs have the predisposition to complications like hypoxemia, hemoptysis, ischemic stroke and cerebral abscess. Treatment is recommended to prevent later complications by embolization or surgical lobectomy. Herein, we

\footnotetext{
* Correspondence: 1183020@zju.edu.cn
Department of Cardiovascular Surgery, the First Affiliated Hospital, College of

* Correspondence: 1183020@zju.edu.cn Medicine, Zhejiang University, 79\#, Qingchun Road, Hangzhou 310000, Zhejiang, China
}

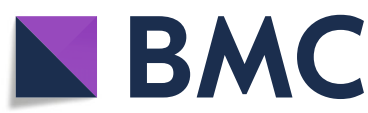

(c) The Author(s). 2020 Open Access This article is licensed under a Creative Commons Attribution 4.0 International License, which permits use, sharing, adaptation, distribution and reproduction in any medium or format, as long as you give appropriate credit to the original author(s) and the source, provide a link to the Creative Commons licence, and indicate if changes were made. The images or other third party material in this article are included in the article's Creative Commons licence, unless indicated otherwise in a credit line to the material. If material is not included in the article's Creative Commons licence and your intended use is not permitted by statutory regulation or exceeds the permitted use, you will need to obtain permission directly from the copyright holder. To view a copy of this licence, visit http://creativecommons.org/licenses/by/4.0/ The Creative Commons Public Domain Dedication waiver (http://creativecommons.org/publicdomain/zero/1.0/) applies to the data made available in this article, unless otherwise stated in a credit line to the data.

\section{Case report}

A 23-year-old male was admitted to the department of hematology because of elevated hemoglobin during routine check-up. Physical examination revealed digital clubbing, cyanosis of oral mucosa and extremities. Remarkable signs of laboratory work up included decreased

report a 23-year-old male who presented with elevated were misinterpreted as the sequela of previous tuberculosis (TB). Our case showed great learning value of differential diagnosis in patients with PAVMs. Furthermore, a brief literature review of PAVMs was performed. 
$\mathrm{O}_{2}$ saturation on room air of about $85 \%$ and elevated hemoglobin of about $23.0 \mathrm{~g} / \mathrm{dl}$. Chest roentgenogram suggested remote infectious lesion in the left upper lobe (Fig. 1a) and echocardiography showed no cardiac malformation. Additionally, the patient reported history of TB in his childhood and had been treated with standard anti-TB therapy for almost 1 year. Family members reported no history of repeated nosebleed, anemia or similar features mentioned above. The patient had been informed by his doctor that his clubbed fingers were sequela of chronic hypoxia caused by $\mathrm{TB}$ and the left pulmonary lesion was residual TB lesion after standard treatment. Bone marrow examination demonstrated non-specific erythroid hyperplasia. The initial diagnosis made by hematologist was polycythemia vera and hydroxyurea was applied. After several courses of treatment, the patient's hemoglobin still kept high $(22.5 \mathrm{~g} / \mathrm{dl})$ without obvious change and cardiothoracic consultation was scheduled. Considering the digital clubbing, cyanosis of oral mucosa and extremities, elevated hemoglobin, low $\mathrm{O}_{2}$ saturation and left pulmonary lesion, PAVMs were suspected. CT pulmonary angiography showed abnormal communications between the left upper pulmonary arteries and veins and PAVMs of left lingual lobe was confirmed (Fig. 1b). No extrapulmonary vascular malformations were detected.
Since PAVMs were diffuse but restricted to left upper lobe of lung, complete feeding arteries embolization was difficult and the patient finally received video assisted thoracoscopic left upper lobectomy. Intraoperatively, diffusely dilated and angiomatous vessels with hemorrhagic tendency were detected on the surface of left upper lobe (Fig. 1c, d). The left superior pulmonary vein, left upper lobe bronchus and left superior pulmonary artery were resected by endo-stapler, respectively. After left upper lobectomy, the $\mathrm{O}_{2}$ saturation immediately increased to $98 \%$.

The histopathological examination confirmed the diagnosis of PAVMs. The patient was discharged home on the 5 th postoperative day with hemoglobin level of $19.2 \mathrm{~g} / \mathrm{dl}$. Three months after surgery, the symptom of cyanosis relieved and hemoglobin was down to almost normal level of $14.9 \mathrm{~g} / \mathrm{dl}$. So far, the patient has been followed up for about 5 years without occurrence of cyanosis, dyspnea, decreased $\mathrm{O}_{2}$ saturation or increased hemoglobin level.

\section{Discussion}

PAVMs are defined as abnormal communications between pulmonary arteries and veins without intervening capillary bed. Its prevalence is approximately 1 in 2630 in population scanned by chest CT with a slight predilection
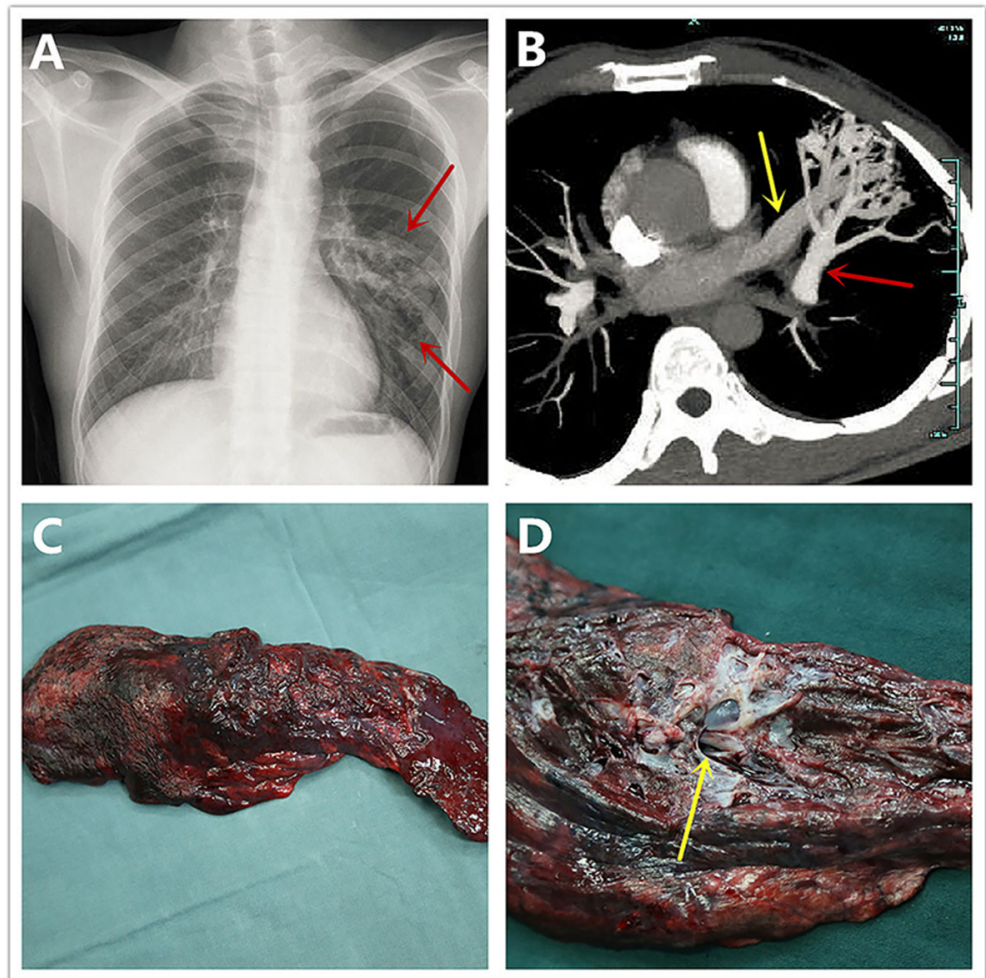

Fig. 1 a Chest roentgenogram detected the lesions (in red arrows) in the left upper lobe which were initially considered as residual TB lesions. b CT pulmonary angiography showed abnormal communications between the left superior pulmonary vein (in yellow arrow) and left superior pulmonary artery (in red arrow). $\mathbf{c}$, d Surgical specimen (excised left upper lobe) showed the diffusely tortuous vessels all over the lobe and the vascular cavities were extremely dilated (in yellow arrow). TB: tuberculosis; CT: computed tomography 
for female [1, 3]. PAVMs can be sporadic, multiple or even diffuse lesions as well as uni- or bi-lateral involved. PAVMs often have lower lobe predominance. Histopathologically, PAVMs manifest as tortuous or direct aneurysmal connection developing between arteries and veins without intervening capillary bed, which led to the loss of "filter capacity".

The etiology of PAVMs could be congenital or acquired. The majority of PAVMs are associated with autosomal dominant disorder called hereditary hemorrhagic telangiectasia (Osler-Weber-Rendu syndrome) [4]. Acquired PAVMs are usually secondary to liver cirrhosis, infections, metastatic carcinomas, chest trauma and iatrogenic procedures [3]. Patients with PAVMs are usually asymptomatic, especially in children. The common pulmonary symptoms include cyanosis of oral mucosa and extremities, digital clubbing, hemoptysis and chest pain. Extrapulmonary manifestations are polycythemia, cerebral abscess, stroke or transient ischemic attack, epistaxis and so on [5]. In our patient, the hypoxemia as well as polycythemia were consequences of right-to-left shunt caused by PAVMs and were responsible for further presentations like digital clubbing and cyanosis.

In our case, the patient was initially treated as polycythemia vera. There might be several reasons why the other clinical features were neglected. First, the history of TB made the doctors regard the pulmonary lesion as residual TB lesion. Second, TB is able to cause cyanosis and digital clubbing when severe hypoxemia occurs, which could explain the patient's cyanosis and clubbed fingers since he was a child. We should draw lessons from this case that PAVMs should be suspected when the following combination of clinical manifestations coexists: central cyanosis, digital clubbing, hypoxemia, hemoptysis, elevated hemoglobin, pulmonary lesions on chest roentgenogram or CT, history of cerebral abscess and so on.

Echocardiography findings of PAVMs might suggest increased left heart volume overload. Chest roentgenogram could detect abnormal lesions in PAVMs region but with low specificity. CT pulmonary angiography is of great diagnostic value. Pulmonary angiography is regarded as the gold standard for diagnosis, especially when a therapeutic intervention is planned. In patients who are allergic to iodinated contrast, contrast-enhanced transthoracic echocardiography is highly recommended to be used as a diagnostic method, in which early appearance of microbubbles in the left atrium strongly suggests the existence of PAVMs [3].

The natural history of PAVMs is relatively predictable because of its tendency to increase in size. If untreated, the mortality rate of untreated symptomatic patients ranges from 4 to $22 \%$ and even up to $40 \%$ in severe cases [6]. Spontaneous regression has rarely been reported.
There is consensus about early intervention in patients with PAVMs to prevent later complications like systemic embolization, pulmonary hemorrhage, ischemic stroke, cerebral abscess, congestive heart failure and so on. Treatment strategy of PAVMs should be made by taking multiple factors such as size, number, location and complications into consideration. Embolization is recommended as first-line treatment for PAVMs [7] while surgical lobectomy is recommended when PAVMs are diffuse, large and restricted to one lobe [8].

\section{Conclusion}

We experienced a meaningful case with PAVMs which was initially treated as TB and polycythemia vera. We emphasize the importance of maintaining clinical suspicion of PAVMs in patients with features of central cyanosis, digital clubbing, hypoxemia, hemoptysis, elevated hemoglobin, pulmonary lesions on chest roentgenogram or CT, history of cerebral abscess and so on. Surgical lobectomy is suitable for PAVMs which are diffuse, large and restricted to one lobe.

\section{Abbreviations}

PAVM: Pulmonary arteriovenous malformation; CT: Computed tomography; TB: Tuberculosis

\section{Acknowledgements \\ Not applicable.}

\section{Authors' contributions}

PT drafted the manuscript. PT, WDL and YMN participated in the treatment YMN contributed to the development of methodology. All authors read and approved the final manuscript.

\section{Funding}

This work was supported by grants from Zhejiang Medical and Health Science and Technology Projects of China [Project Number: 2018249646].

\section{Availability of data and materials}

Please contact author for data requests.

\section{Ethics approval}

Not applicable.

\section{Consent for publication}

Written informed consent of clinical detail and image publication was obtained from the patient.

\section{Competing interests}

None declare.

Received: 27 July 2020 Accepted: 21 September 2020

Published online: 02 October 2020

\footnotetext{
References

1. Nakayama M, Nawa T, Chonan T, Endo K, Morikawa S, Bando M, et al. Prevalence of pulmonary arteriovenous malformations as estimated by lowdose thoracic CT screening. Intern Med. 2012;51(13):1677-81.

2. Churton T. Multiple aneurysm of pulmonary artery. Br Med J. 1897;1:1223-5.

3. Majumdar S, McWilliams JP. Approach to pulmonary arteriovenous malformations: a comprehensive update. J Clin Med. 2020;9(6):1927.

4. Saboo SS, Chamarthy M, Bhalla S, Park H, Sutphin P, Kay F, et al. Pulmonary arteriovenous malformations: diagnosis. Cardiovasc Diagn Ther. 2018;8(3):325-37.

5. Shovlin CL. Pulmonary arteriovenous malformations. Am J Respir Crit Care Med. 2014;190(11):1217-28.
} 
6. Chowdhury UK, Kothari SS, Bishnoi AK, Gupta R, Mittal CMReddy S. Successful lobectomy for pulmonary arteriovenous malformation causing recurrent massive haemoptysis. Heart Lung Circ. 2009;18(2):135-9.

7. Hsu CC, Kwan GN, Evans-Barns Hvan Driel ML. Embolisation for pulmonary arteriovenous malformation. Cochrane Database Syst Rev. 2018;1:CD008017.

8. Hayashi K, Motoishi M, Horimoto K, Sawai SHanaoka J. Left upper division segmentectomy with a simultaneous displaced bronchus and pulmonary arteriovenous anomalies: a case report. J Cardiothorac Surg. 2018;13(1):40.

\section{Publisher's Note}

Springer Nature remains neutral with regard to jurisdictional claims in published maps and institutional affiliations.

Ready to submit your research? Choose BMC and benefit from:

- fast, convenient online submission

- thorough peer review by experienced researchers in your field

- rapid publication on acceptance

- support for research data, including large and complex data types

- gold Open Access which fosters wider collaboration and increased citations

- maximum visibility for your research: over $100 \mathrm{M}$ website views per year

At $\mathrm{BMC}$, research is always in progress.

Learn more biomedcentral.com/submissions 